\title{
POСІЙСЬКА МOВА
}

УДК 811.161 .1

DOI https://doi.org/10.32838/2710-4656/2021.3-1/12

\author{
Алиева У. Н.
}

Бакинский славянский университет

\section{ВЫРАЖЕНИЕ ПРЯМОГО ОБЪЕКТА В РУССКОМ ЯЗЫКЕ}

У статті досліджуються особливості вираження прямого об'єкта в російській мові. Відомо, що активна граматика передбачає правильний опис подій - від граматичного значення до граматичної форми. Це є важливим чинником під час навчання продуктивної мовленнєвої діяльності. Однією з важливих особливостей граматичного значення в російській мові є вираз значення прямого об'єкта. Під прямим об'єктом розуміється предмет, на який переходить, поширюється дія. У російській мові простий прямий об'єкт - це базовий варіант прямого об 'єкта. Простий прямий об'єкт зазвичай виражсається у формі родового із знахідного відмінків. У статті роз'яснюються такі особливості вираження прямого об'єкта: 1) винятковий (повний або частково винятковий) прямий об'єкт; 2) посилений прямий об'єкт. Аналіз показує, що важсливі правила трунтуються на об'єктивних мовних чинниках. Тут мають місие також позитивні і негативні побудови формулювань. Ці конструкцї згадуються у перетворенні іменника на дієслово й є актуалізаторами прямого об'єкта. Контекст же виступає в ролі визначального чинника семантичного комплексу.

Необхідно відзначити, що правила активної граматики утворюють певну ієрархію і включають: а) обов'язкові вимоги або заборони; б) факультативні рекомендаиії, застосування яких неможливо строго регламентувати, оскільки самі граматичні явища носять стилістичний характер (найбільш яскравий приклад у російській мові - вживання повних і коротких форм прикметників); в) дозвіл на відносно вільне вживання граматичних форм.

Ця стаття містить опис фрагмента граматичної системи російської мови, що відноситься до сфери вираження прямого об'єкта. Опис може бути використано під час викладання російської мови як іноземної. Конкретним предметом виступають закономірності вираження прямого об 'єкта, сформульовані в описі у вигляді правил.

Ключові слова: російська мова як іноземна, прямий об'єкт, значення, форма, особливості вираження, правила, твердження, заперечення.

Постановка проблемы. Как известно, активная грамматика предполагает описание грамматических явлений в направлении от грамматического значения к грамматической форме, что необходимо при обучении продуктивным видам речевой деятельности [8, с. 333-338]. Правила такой грамматики входят в функциональную и коммуникативноориентированную грамматику как составная часть $[1 ; 3]$. При разработке активной грамматики возникают три основных методических вопроса: о характере семантических дефиниций, о типах правил и о принципах отбора материала [5; 7].

Постановка задания. Целью статьи является исследование особенностей выражения прямого объекта в русском языке.

Изложение основного материала. Необходимо отметить, что правила активной грамма- тики образуют определенную иерархию и включают: а) обязательные требования или запреты; б) факультативные рекомендации, применение которых невозможно строго регламентировать, поскольку сами грамматические явления носят стилистический характер (наиболее яркий пример в русском языке - употребление полных и кратких форм прилагательных); в) разрешение на относительно свободное употребление грамматических форм: выпей молоко и выпей молока, не читал эту книгу и не читал этой книги. В последнем случае выбор одной из возможных форм зависит от семантического задания. В случае выпей молоко речь идет о конкретном ограниченном объеме жидкости, глагол имеет значение «исчерпать до дна». В выражении выпей молока предполагается выбор между различными жидкостями (молока, 
а не чая, не кофе), количество жидкости не определено заранее, а глагол означает «употребить в пищу». Как видим, различны пресуппозиции высказываний, по-разному ставится логическое ударение - в одном примере на выпей, в другом на молока.

В выражениях не читал эту книгу - не читал этой книги (выбор между винительным и родительным падежами зависит от того, рассматривается объект как один из многих (родительный) или как единственно предполагаемый в данной ситуации (винительный). Как и в предыдущем примере, с этим связана разница в логическом ударении: не читал эту книгу - не читал этой книги.

Очень часто в случае в) свобода употребления конкурирующих форм ограничивается особенностями контекста или построения фразы. «В контексте могут выступать такие языковые средства, которые актуализируют одно из двух противопоставленных грамматических значений» [4, с. 53]. Сравним возможность выражения не читал никаких книг и невозможность не читал никакие книги. Точно так же можно сказать пей молоко и нельзя пей молока. Свои ограничения накладывает, по-видимому, и актуальное членение: эту книгу я не читал (эту книгу - тема), но: я не читал этой книги (этой книги - рема). Активная грамматика должна включать указание на типичные актуализаторы.

В русском языке к числу важных грамматических значений относится значение прямого объекта. Под прямым объектом (ПО) понимается предмет, на который переходит, распространяется действие, который охватывается действием: ловить рыбу, окружать врага, управлять государством, дом строится рабочими. В таком определении термин «предмет» используется в широком смысле: это может быть лицо, особь, конкретная вещь, абстрактное понятие. Действие может быть физическим: ловит рыбу или психическим: pешает в уме задачу. В русском языке многие глаголы, обозначающие состояние, грамматически ведут себя так, как если бы они выражали действие: любит дочь (ср.: обожает дочь), не боится трудностей (ср.: не избегает трудностей), увлекается спортом (ср.: занимается спортом). В качестве особого, но весьма распространенного случая нужно отметить «нулевую» переходность. Она имеет место тогда, когда само действие по своему характеру как бы отвергает предмет: избегать трудностей, беречься простуды, или когда подобное значение придает действию отрицание не при глаголе: не видеть Севды, не написать письма.

В русском языке грамматическое значение ПО имеет три разновидности, обусловленные семантическими различиями и находящие разное выражение с помощью падежных форм [8, с. 97-98]. Оставляем в стороне вопрос о возможности выражения ПО предложно-падежными формами. На наш взгляд, последний случай должен описываться в том разделе активной грамматики, где речь идет о значении предлогов. Все отмеченное далее будет относиться только к беспредложным формам.

Основным вариантом ПО в русском языке является простой прямой объект (ППО). Его значение совпадает с указанным выше, не имея семантических уточнителей. Обычно ППО выражается винительным падежом, при некоторых трансформациях - именительным и родительным [2; 7]. ППО является немаркированным членом внутриобъектной оппозиции. Это значит, что в определенных контекстах его противопоставление другим видам ПО нейтрализуется, причем в позиции нейтрализации выступает именно ППО, например: допить вино - выпить вина упиться вином / пить вино.

В данном случае позиция нейтрализации создается контекстом с глаголом пить, при этом независимо от значения употребляется одна и та же форма винительного падежа: Сегодня мы пьем сухое вино. Он пил вино как бы нехотя. Mbl заметили, что ты все чаще и чаще пьешь вино. Исключения носят кажущийся характер: $T b l$ что-то много стал пить вина - в этом предложении форма род. п. существительного вино управляется не глаголом, а неопределенным числительным много.

Итак, ППО употребляется как заместитель других разновидностей прямого объекта. Каковы же эти разновидности?

На втором месте по употребительности после ППО стоит значение прямого объекта с исключением (ПОИ). Оно имеет два варианта - с полным и частичным исключением (обозначаем соответственно ПОЙ и ПОЙ $)$. ПОИ п - такой прямой объект, который по смыслу фразы исключается из сферы действия или состояния: избегать неприятностей, бояться грозы, не поймать рыбы, не любить манной каши. Выше мы назвали этот случай нулевой переходностью действия.

Грамматическое значение ПОИ тогда, когда действие распространяется не на весь предмет (предметы), а лишь на его часть (на 
часть однородных предметов): выпить вина - не все вино, отрезать хлеба - отделить часть хлеба, избегать трудной работы - не всякой работы, не прочел ни одной книги - из многих возможных.

Оба варианта ПОИ выражаются родительным падежом, поэтому на практике их различение не всегда является необходимым. Однако различие существует и может проявляться в наличии/отсутствии параллельных конструкций с ППО: выпить молока - выпить молоко, избегать неприятноcmeй - (конструкция с вин. п. отсутствует).

Наименее распространенной и все же обязательной для выражения является третья разновидность ПО - прямой объект усиленный (УПО). Значение УПО выражается при глаголах, обозначающих действие интенсивное или глобальное, которое охватывает предмет многосторонне и целиком. УПО - предмет, охваченный действием полностью через сумму конкретных и постоянных актов. Примеры: управлять государством, владеть языком, упиться вином. УПО выражается творительным падежом.

1. Выражение ППО. Как было отмечено выше, ППО является немаркированной разновидностью прямого объекта. В речи он встречается значительно чаще других разновидностей, поэтому общее правило употребления ППО будет носить, так сказать, отрицательный характер.

Правило 1. ППО употребляется во всех случаях, когда другие правила не требуют употребления ПОИ или УПО. Это правило носит характер полного или частичного разрешения. Случаи частичного разрешения будут специально оговорены как ограничения на правила употребления ПОИ и УПО. Здесь необходимо отметить только падежное выражение ППО в позициях различения разновидностей и в типичных позициях нейтрализации.

Правило 2. В позициях, где ППО противопоставлен ПОИ или УПО, он выражается формой винительного падежа.

Правило 3 (обязательное). При пассивной трансформации противопоставление разновидностей ПО нейтрализуется в варианте ППО. ПО выражается формой именительного падежа. Например: Мальчик читает книгу - Книга читается мальчиком; Мы избегаем трудностей - Трудности не избегаются нами; Народ управляет государством - Государство управляется народом.

Правило 4 (обязательное). При трансформации глагола в существительное противопоставление ППО и ПОИ нейтрализуется в варианте ППО. ППО выражается формой родительного падежа.
Например: читать книгу - чтение книги; починить обувь - починка обуви; ремонтировать здание ремонт здания; бояться грозы - боязнь грозы; не выполнить приказа - невыполнение приказа.

Трансформация, указанная в этом правиле, понимается как семантическая, а не как словообразовательная, поэтому в один ряд выстраиваются не только случаи типа читать - чтение, но и случаи с обратным направлением деривации: ремонтировать - ремонт.

УПО этим правилом не затрагивается: управлять государством - управление государством; заниматься спортом - занятия спортом.

2. Выражение ПОИ . ПОИ пыражается родительным падежом во всех случаях своего употребления. ПОИ п употребляется:

Правило 5 (обязательное). ПОИ п фигурирует при глаголах, семантика которых указывает на исключение объекта из сферы действия: cmpaииться, пугаться, бояться, стесняться, стьдиться, опасаться, беречься, достигать, также производные от них и видовые пары (например, перепугаться, достигнуть), избегать/избегнуть. Примеры: стылиться бедности, беречься простуды. Употребление ПОИ п сохраняется при этих глаголах и в том случае, когда глагол получает отрицание в виде частицы не: не стыдиться бедности, не беречься простуды.

Правило 6 (факультативное). ПОИ может употребляться при глаголах, не указанных в правиле 5 , если эти глаголы имеют при себе отрицание не: не вижу смысла, не терплю возражений.

Конкретизацию этого правила целесообразно проводить особо, так как в конструкции «не + глагол + ПО» разграничение ПОИ п ПОИ ляет серьезные трудности. Практическая полезность такого разграничения невелика, поскольку обе разновидности ПОИ выражаются одним падежом. Правила, действующие в указанной конструкции, выносятся в специальный раздел (исключая случаи, оговоренные в правилах 5 и 7).

3. Выражение ПОЙ : ПОИ ется родительным падежом. ПОИ употребляется:

Правило 7 (обязательное). ПОИ ч употребляется, когда дополнение выражено вещественным существительным и обозначает часть вещества, а глагол стоит в форме СВ или имеет отрицание. Примеры: купить хлеба, отрезать колбасы, налить молока, не наливать молока.

Актуализаторами значения ПОИ ч выступают глаголы с приставками noд-, до-, om-, из- и значением добавления или отделения части вещества: подлить воды, досыпать крупь, отрезать кол- 
басы, испить водицьь и глаголы с приставкой по-, обозначающие неполное, ограниченное действие: попить молока, поесть хлеба. Следует иметь в виду многозначность приставок, вследствие чего имеются параллельные конструкции с другим значением: поесть хлеба «съесть немного хлеба»- поесть хлеб «съесть весь хлеб» [5, с. 69]. При отсутствии актуализаторов также возможны параллельные конструкции с ППО: купить хлеб, выпить молоко, не выпивать молоко.

Формулировка правила 7 содержит ограничение: при глаголах НСВ без отрицания употребляется только ППО: покупать хлеб, отрезать колбасу, наливать молоко.

Правило 8 (факультативное). ПОИ употребляться при глаголах с отрицанием не: не исправил одной опечатки, не любил трудной pаботы.

Правило 9 (обязательное). ПОИ ч употребляется при глаголах с приставкой на-, имеющих значение действия, охватившего часть однородных предметов и достигшего при этом желаемой или возможной для субъекта полноты: нарвать ияветов, напечь пирогов, наслушаться песен.

4. Выражение ПОИ и ППО в конструкциях «не + глагол + ПО». В данном разделе конкретизируются правила 6 и 8. В отрицательной конструкции зачастую трудно бывает разграничить значения ПОИ $и$ и ПОИ может иметь, по-видимому, различные пресуппозиции [6]. Так, в предложении Этой книги я не читал реализуется ПОИ незнакомство именно с данной книгой (например, в контексте $C$ творчеством этого писателя знаком неплохо. Но этой книги я не читал). Пресуппозиция исключает одну книгу из всего, написанного этим писателем. В другом контексте Вообще не знаю этого писателя, и этой книги тоже не читал множество объектов, составляющих ПО, рассматривается как включающее один элемент. Поэтому исключение полное.

Семантическая двойственность отрицательных конструкций подсказывает целесообразность суммарного описания их без различения ПОИ и ПОИ описания от значения к форме. Обособленное рассмотрение таких конструкций, в конечном счете, оправдано тем, что в них проявляется новый семантический фактор - отрицание.

Правило 10 (рекомендующее). В отрицательных конструкциях преобладает ПОИ. Можно выделить ряд актуализаторов этого значения (кроме указанных в правилах 5, 7 и 9).
Актуализируется ПОИ, когда в позиции прямого объекта стоит абстрактное существительное: не видел смысла, не имел желания. Актуализатором ПОИ является форма деепричастия (в связи с присущим ей значением дополнительной предикативности): Не зная броду, не суйся в воду; Не прочитав книги, всюду ругал ее. В этих случаях дополнительно влияет на выбор ПОИ форма множественного числа существительного, выражающего ПО. Она подчеркивает избирательность отрицания: не получить указаний, не слушая возражений.

Способствует реализации ПОИ положение ПО в позиции темы высказывания: Севды я давно не видел (подчеркнута рема), ср.: Севду я давно не видел, а с Ахмедом встретился вчера.

Во многих случаях в отрицательной конструкции с ПОИ конкурирует ППО. Общим правилом является такое:

Правило 11 (разрешающее). В отрицательной конструкции употребляется ППО, когда значение отрицания сосредоточивается на глаголе, не выходя за рамки предиката.

Актуализатором ППО в рассматриваемых конструкциях являются имена собственные в позиции ПО: Брат не обманул Севду; не нашел на небе Орион; в таких предложениях наиболее четко выражается трехчленная логическая структура «субъект + предикат + объект», вследствие чего значение отрицания сосредоточивается в рамках предиката.

Другой актуализатор ППО - принадлежность ПО реме высказывания: Не одобряю твою поспешность, твои метания.

В отрицательных конструкциях может актуализировать ППО омонимическое отталкивание, возникающее при совпадении форм родительного единственного и винительного множественного: не читать газету (не читать газеты двусмысленно: одну или много?).

5. Выражение УПО. Эта разновидность прямого объекта выражается формой творительного падежа.

Правило 12 (обязательное). УПО употребляется при глаголах: гордиться, дышиать, жить, заниматься, играть, интересоваться, пользоваться, любоваться, обойтись, руководить, щутить, владеть, возмущаться, управлять, заведовать, распоряжаться, командовать: гордиться происхождением, заниматься спортом, дыпать воздухом, жить страстями и идеями времени, играть человеком, пользоваться случаем, управлять заводом. 
Выводы и предложения. Итак, в статье описываются факторы, влияющие на выбор одной из разновидностей прямого объекта и в конкретном высказывании на русском языке.
В процессе преподавания материал может быть упрощен в соответствии с уровнем коммуникативной компетенции обучаемых - по этапам обучения.

\section{Список литературы:}

1. Бондарко А. В. Грамматическая категория и контекст. Ленинград : Наука, 1971.

2. Вагабова Х. Д. Я научу вас говорить по-русски : учебное пособие. Баку, 2019.

3. Забавников Б. Н. О двух уровнях конвенциональности языка в коммуникативно-ориентированной грамматике. НДВШ. Филологические науки. 1982. № 2. С. 80-83.

4. Ковтунова И. И. Современный русский язык. Порядок слов и актуальное членение предложения. Москва : Просвещение, 1976.

5. Кожанова Н. И. Структурно-семантические особенности современной устной разговорной речи в практике обучения русскому языку как иностранному. Современные проблемы лингвистики и методики преподавания русского языка в вузе и школе. 2008. Вып. 5. С. 65-72.

6. Мамедов Н. Ш. Отрицательное предложение в современном русском языке : методическое пособие. Баку : Мутарджим, 2000.

7. Практическая методика обучения русскому языку как иностранному / под ред. А. Н. Щукина. Москва : Русский язык, 2003.

8. Розенталь Д. Э. Управление в русском языке. Москва : Русский язык, 1981. С. 97-98.

9. Щерба Л. В. Языковая система и речевая деятельность. Ленинград : Наука, 1974.

\section{Aliyeva U. N. EXPRESSION OF A DIRECT OBJECT IN RUSSIAN LANGUAGE}

The article discusses the regularities of the expression of a direct object in Russian. It is known that active grammar involves the description of grammatical phenomena in the direction from grammatical meaning to grammatical form. This is necessary when teaching productive types of speech activity. In Russian, one of the important grammatical meanings is the meaning of a direct object. A direct object is understood as an object to which the action is transferred and extended. The main variant of a direct object in Russian is a simple direct object. The simple direct object is usually expressed in the accusative or genitive forms. The features of a direct object are described in detail: 1) direct object with exclusion (with full or partial exclusion); 2) enhanced straight object. The rules are formulated, both mandatory and optional, based on objective linguistic factors. A certain place is given to the opposition of affirmative and negative constructions. Transformations of verbs into nouns and actualizers of a direct object in the constructions under consideration are noted. At the same time, the context is the determining factor of the semantic complex.

It should be noted that the rules of active grammar form a certain hierarchy and include: a) mandatory requirements or prohibitions; b) optional recommendations, the use of which cannot be strictly regulated, since the grammatical phenomena themselves are stylistic in nature (the most striking example in Russian is the use of full and short forms of adjectives); c) permission for relatively free use of grammatical forms.

This article contains a description of a fragment of the grammatical system of the Russian language related to the field of expression of a direct object. The description can be used when teaching Russian as a foreign language. The specific subject is the patterns of expression of the direct object, formulated in the description in the form of rules.

Key words: Russian as a foreign language, direct object, meaning, form, regularities of the expression, rules, affirmation, negation. 